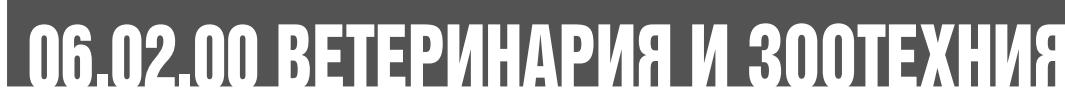

УДК 636.061.4

DOI 10.18286/1816-45-2017-4-98-102

\section{СРАВНИТЕЛЬНАЯ ХАРАКТЕРИСТИКА ЭКСТЕРЬЕРА КОРОВ МЯСНОГО НАПРАВЛЕНИЯ ПРОДУКТИВНОСТИ}

\author{
Алексеева Елена Ивановна, кандидат сельскохозяйственных наук, доцент кафедры «Химия и экспер- \\ тиза продовольственных товаров» \\ Суханова Светлана Фаилевна, доктор сельскохозяйственных наук, профрессор кафедры «Химия и экс- \\ пертиза продовольственных товаров» \\ Лещук Татьяна Леонидовна, доктор сельскохозяйственных наук, доцент кафедры «Частная зоотех- \\ ния, кормление и разведение животных» \\ ФГБОУ ВО «Курганская государственная сельскохозяйственная академия имени Т.С. Мальцева» \\ 641300, Курганская обл., Кетовский р-н, с. Лесниково; телефон/факс: +7(35231)4-41-40; \\ e-mail: rectorat@mail.ksaa.zaural.ru
}

Ключевые слова: крупный рогатый скот, коровы, промеры тела.

В настоящее время оценка внешних форм животного, выявление взаимосвязи между экстерьером и продуктивностью - важнейшая задача селекционеров. Исследования особенностей экстерьера коров абердин-ангусской $(n=44)$ и герефордской $(n=39)$ пород проводились в хозяйствах Курганской области согласно инструкции «Порядок и условия проведения бонитировки племенного крупного рогатого скота мясного направления продуктивности». Анализ экстерьерных показателей показал, что коровы абердин-ангусской породы были выше и крупнее животных герефордской породы. Так, разница по высоте в холке и крестце составила 10,00 ( $P<0,001)$ и 11,55 cм (P<0,001) соответственно. Глубина, ширина и обхват груди были больше у коров абердин-ангусской породы на 2,55 (P<0,05), 3,04 (P<0,001) и 18,63 (P<0,001) см соответственно, косая длина туловища - на 12,88 см (P<0,001), обхват пясти - на 2,4 см (P<0,001). Индексы телосложения коров абердин-ангусской породы имели большие значения, чем коров герефордской породы: длинноногости - на 4,5 \%, растянутости - на 1,0\%, тазогрудной - на 3,9\%, грудной - на 3,9\%, сбитости - на 1,1 \%, перерослости на 0,7\%, массивности - на 2,1\%, широтный - на 20,6\% (P<0,001), широкотелости - на 1,1\% соответственно. Оценка экстерьера коров позволила установить, что животные абердин-ангусской породы имели лучшие мясные формы, чем герефордской.

\section{Введение}

В теорию животноводства понятие экстерьер было введено в 1768 году К. Буржелем, и понималось оно как «наружные формы телосложения в целом или внешний вид животного» [1].

B XIX веке при выведении специализированных пород была установлена связь между статями тела животных и их продуктивностью, но, как правило, отбор по отдельным статям приводил к ослаблению конституции и появлению пороков экстерьера. Оценка экстерьера играет важную роль в племенной работе, так как дает надежное представление о крепости конституции и здоровье животных [2, 3]. Этот факт отмечен в работах таких ученых, как М.И. Придорогин, В.И. Всеволодов, П.Н. Кулешов, Е.А. Богданов, М.Ф. Иванов, Е.Ф. Лискун и др. Было доказано, что на основе внешнего осмотра и измерений можно сделать заключение о развитии внутренних органов животных, их конституциональной крепости, здоровье, породных особенностях, соответствии особенностей телосложения направлению продуктивности, приспособленности к условиям содержания. Так, у 
Промеры тела коров, см

\begin{tabular}{|c|c|c|c|c|c|}
\hline \multirow[b]{2}{*}{ Показатель } & \multirow{2}{*}{$\begin{array}{c}\text { Промер } \\
\text { желательного } \\
\text { типа }\end{array}$} & \multicolumn{2}{|c|}{ Абердин-ангусская порода (п=44) } & \multicolumn{2}{|c|}{ Герефордская порода (п=39) } \\
\hline & & $\overline{\tilde{O}} \pm S \overline{\tilde{o}}$ & $C v, \%$ & $\overline{\tilde{O}} \pm S \overline{\tilde{O}}$ & $C v, \%$ \\
\hline Высота в холке & $125-130$ & $126,36 \pm 0,55$ & 3 & $116,36 \pm 0,58$ & 3 \\
\hline Высота в крестце & $123-135$ & $133,93 \pm 0,59$ & 3 & $122,38 \pm 0,55$ & 4 \\
\hline Глубина груди & $68-72$ & $64,11 \pm 0,58$ & 6 & $61,56 \pm 0,15$ & 2 \\
\hline Ширина груди & $48-50$ & $41,27 \pm 0,62$ & 10 & $38,23 \pm 0,47$ & 8 \\
\hline Ширина в маклоках & $49-52$ & $50,75 \pm 0,33$ & 4 & $49,95 \pm 0,31$ & 4 \\
\hline Косая длина туловища & $145-153$ & $145,14 \pm 1,01$ & 5 & $132,26 \pm 0,80$ & 4 \\
\hline Обхват груди & $190-195$ & $187,68 \pm 1,12$ & 4 & $169,05 \pm 1,17$ & 4 \\
\hline Обхват пясти & $18-20$ & $19,68 \pm 0,10$ & 3 & $17,28 \pm 0,07$ & 3 \\
\hline
\end{tabular}

мясного скота форма тела имеет вид параллелепипеда, туловище глубокое и широкое, ноги короткие, широко и отвесно поставленные, мускулатура развита хорошо. Голова и шея короткие, толстые, спина и поясница ровные, широкие, мясистые, зад широкий, хорошо выполнен мускулатурой, кожа рыхлая [4].

В настоящее время оценка внешних форм животного, выявление взаимосвязи между экстерьером и продуктивностью - важнейшая задача селекционеров.

\section{Объекты и методы исследований}

Нами была проведена оценка экстерьера коров абердин-ангусской и герефордской пород в хозяйствах Курганской области согласно инструкции «Порядок и условия проведения бонитировки племенного крупного рогатого скота мясного направления продуктивности» [5]. Для исследования были отобраны коровы второго отела: абердин-ангусская порода - 44 головы, герефордская - 39. Учитывали следующие промеры: высота в холке, высота в крестце, глубина груди, ширина груди, косая длина туловища, ширина в маклоках, обхват пясти. Затем рассчитывали индексы телосложения животных: длинноногости, растянутости, тазогрудной, грудной, сбитости, перерослости, костистости, массивности, широтный, широкотелости.

\section{Результаты исследований}

В таблице 1 представлены результаты экстерьерной оценки коров абердин-ангусской и герефордской пород.

В ходе исследования было установлено, что высота в холке у коров абердин-ангусской породы составила 126,36 см, что находится в пределах значения промера желательного типа. Высота в крестце была 133,93 см, что характеризует коров как высокорослых и соответствует стандарту. Глубина груди опытных животных оказалась 64,11 см, а ширина груди - 41,27 см, что меньше желательных значений промеров. Промер «ширина в маклоках» согласуется со стандартом породы и равен 50,75 см. Косая длина туловища составила 145,14 см, что соответствует минимальному значению стандарта. Обхват груди - 187,68 см, это меньше желательного значения. Обхват пясти - 19,68 см, это в пределах нормы.

Промеры тела коров герефордской породы были ниже стандартных значений, кроме промера «ширина в маклоках». Так, коровы герефордской породы имели высоту в холке 116,36 см, высоту в крестце - 122,38 см, глубину, ширину и обхват груди - 61,56, 38,23 и 169,05 cм соответственно, косую длину туловища - 132,26 см, обхват пясти - 17,28 см. Промер «ширина в маклоках» был равен 49,95 см, т. е. согласовался со стандартом.

Анализ экстерьерных показателей показал, что коровы абердин-ангусской породы были выше и крупнее животных герефордской породы. Так, разница по высоте в холке и крестце составила 10,00 ( $\mathrm{P}<0,001)$ и 11,55 cм ( $\mathrm{P}<0,001)$ соответственно. Глубина, ширина и обхват груди были больше у коров абердин-ангусской породы на 2,55 ( $\mathrm{P}<0,05), 3,04(\mathrm{P}<0,001)$ и 18,63 $(P<0,001)$ см соответственно, косая длина туловища - на 12,88 см $(P<0,001)$, обхват пясти - на $2,4 \mathrm{~cm}(\mathrm{P}<0,001)$.

Результаты балльной оценки экстерьера представлены в таблице 2.

Телосложение коров абердин-ангусской породы было оценено в 14,66 баллов из 15 возможных, что характеризует их как животных крупного телосложения с широким и округлым туловищем и хорошо выраженным мясным типом породы. Мускулатура коров хорошо развита, костяк крепкий, но не грубый - 9,84 балла. Голова легкая, несколько сужается к затылку и выдается во лбу, шея широкая и короткая, хо- 
Таблица 2

Результаты балльной оценки экстерьера, балл

\begin{tabular}{|l|c|c|c|c|c|}
\hline \multirow{2}{*}{\multicolumn{1}{c|}{ Показатель }} & \multirow{2}{*}{ Высший балл } & \multicolumn{2}{c|}{$\begin{array}{c}\text { Абердин-ангусская } \\
\text { порода (п=44) }\end{array}$} & \multicolumn{2}{c|}{ Герефордская порода (п=39) } \\
\cline { 3 - 6 } & & $\bar{O} \pm S \overline{\tilde{O}}$ & $\mathrm{Cv}, \%$ & $\overline{\tilde{O}} \pm S \overline{\tilde{O}}$ & \multicolumn{2}{c|}{ Cv, \% } \\
\hline Телосложение & 15 & $14,66 \pm 0,18$ & 8 & $10,92 \pm 0,13$ & 8 \\
\hline Мускулатура & 10 & $9,84 \pm 0,09$ & 6 & $7,13 \pm 0,09$ & 8 \\
\hline Голова, шея & 5 & $5,00 \pm 0,00$ & 0 & $5,00 \pm 0,00$ & 0 \\
\hline Грудь & 10 & $9,34 \pm 0,14$ & 10 & $6,00 \pm 0,08$ & 9 \\
\hline Холка, спина, поясница & 15 & $15,00 \pm 0,00$ & 0 & $11,46 \pm 0,11$ & 6 \\
\hline Крестец & 10 & $9,68 \pm 0,11$ & 7 & $8,33 \pm 0,11$ & 8 \\
\hline Окорока & 10 & $10,00 \pm 0,00$ & 0 & $7,26 \pm 0,11$ & 10 \\
\hline Вымя & 15 & $15,00 \pm 0,00$ & 0 & $14,77 \pm 0,07$ & 3 \\
\hline Конечности & 10 & $10,00 \pm 0,00$ & 0 & $9,90 \pm 0,05$ & 3 \\
\hline Общий балл & 100 & $98,52 \pm 0,25$ & 2 & $80,77 \pm 0,31$ & 2 \\
\hline
\end{tabular}

Таблица 3

Индексы телосложения коров

\begin{tabular}{|c|c|c|c|c|c|}
\hline \multirow[b]{2}{*}{ Показатель } & \multirow{2}{*}{$\begin{array}{c}\text { Индексы } \\
\text { телосложения, } \\
\text { характерные для } \\
\text { мясного скота (по Е.Я. } \\
\text { Борисенко) }\end{array}$} & \multicolumn{2}{|c|}{$\begin{array}{c}\text { Абердин-ангусская порода } \\
(n=44)\end{array}$} & \multicolumn{2}{|c|}{ Герефордская порода (п=39) } \\
\hline & & $\overline{\tilde{O}} \pm S \overline{\tilde{O}}$ & $\mathrm{Cv}, \%$ & $\overline{\tilde{O}} \pm S \overline{\tilde{o}}$ & $C v, \%$ \\
\hline Длинноногости & 42,5 & $49,24 \pm 0,45$ & 6 & $47,04 \pm 0,30$ & 4 \\
\hline Растянутости & 122,5 & $114,86 \pm 0,65$ & 4 & $113,71 \pm 0,68$ & 4 \\
\hline Тазогрудной & 86 & $81,38 \pm 1,08$ & 9 & $81,52 \pm 1,06$ & 8 \\
\hline Грудной & 73,5 & $64,62 \pm 1,17$ & 12 & $62,13 \pm 0,81$ & 8 \\
\hline Сбитости & 132,5 & $129,48 \pm 0,87$ & 4 & $128,00 \pm 1,19$ & 6 \\
\hline Перерослости & 101 & $106,00 \pm 0,28$ & 2 & $105,21 \pm 0,37$ & 2 \\
\hline Костистости & 13,2 & $15,58 \pm 0,09$ & 4 & $14,86 \pm 0,08$ & 3 \\
\hline Массивности & 155,8 & $148,57 \pm 0,82$ & 4 & $145,42 \pm 1,25$ & 5 \\
\hline Широтный & 212,2 & $193,25 \pm 2,43$ & 8 & $153,45 \pm 4,57$ & 19 \\
\hline Широкотелости & 270,4 & $295,73 \pm 2,30$ & 5 & $292,33 \pm 2,21$ & 5 \\
\hline
\end{tabular}

рошо обмускулена - 5,00 балла. Грудь коров достаточно широкая и глубокая, без впадин за лопатками - 9,34 балла. Холка, спина, поясница были оценены в 15,00 баллов. Холка широкая и мясистая, верхняя линия спины ровная, спина и поясница широкие с хорошо развитой мускулатурой. Крестец ровный, широкий и длинный, хорошо заполненный мускулатурой, хвост правильно посаженный - 9,68 баллов. Окорока оценены в 10,00 балла, характеризуются хорошо развитой мускулатурой, спускающейся до скакательного сустава. Вымя хорошо развитое, правильной формы - 15,00 баллов. Конечности правильно поставленные, с крепкими копытами - 10,00 баллов. Общий балл составил 98,52 из 100 возможных баллов.

Телосложение коров герефордской породы было оценено в 10,92 балла из 15 воз- можных, так как животные были низкого роста в сравнении со стандартом. Мускулатура коров недостаточно хорошо развита - 7,13 балла. Голова легкая, несколько сужается к затылку и выдается во лбу, шея широкая и короткая, хорошо обмускулена - 5,00 баллов. Грудь коров недостаточно широкая - 6,00 баллов. Холка, спина, поясница получили 11,46 балла. Крестец несколько свислый - 8,33 балла. Окорока оценены в 7,26 балла, так как мускулатура недостаточно хорошо выполнена. Вымя хорошо развитое, правильной формы - 14,77 балла. Конечности правильно поставленные, с крепкими копытами - 9,90 балла. Общий балл составил 80,77 из 100 возможных баллов.

Коровы абердин-ангусской и герефордской пород получили практически одинаковое количество баллов за голову и шею, вымя, ко- 


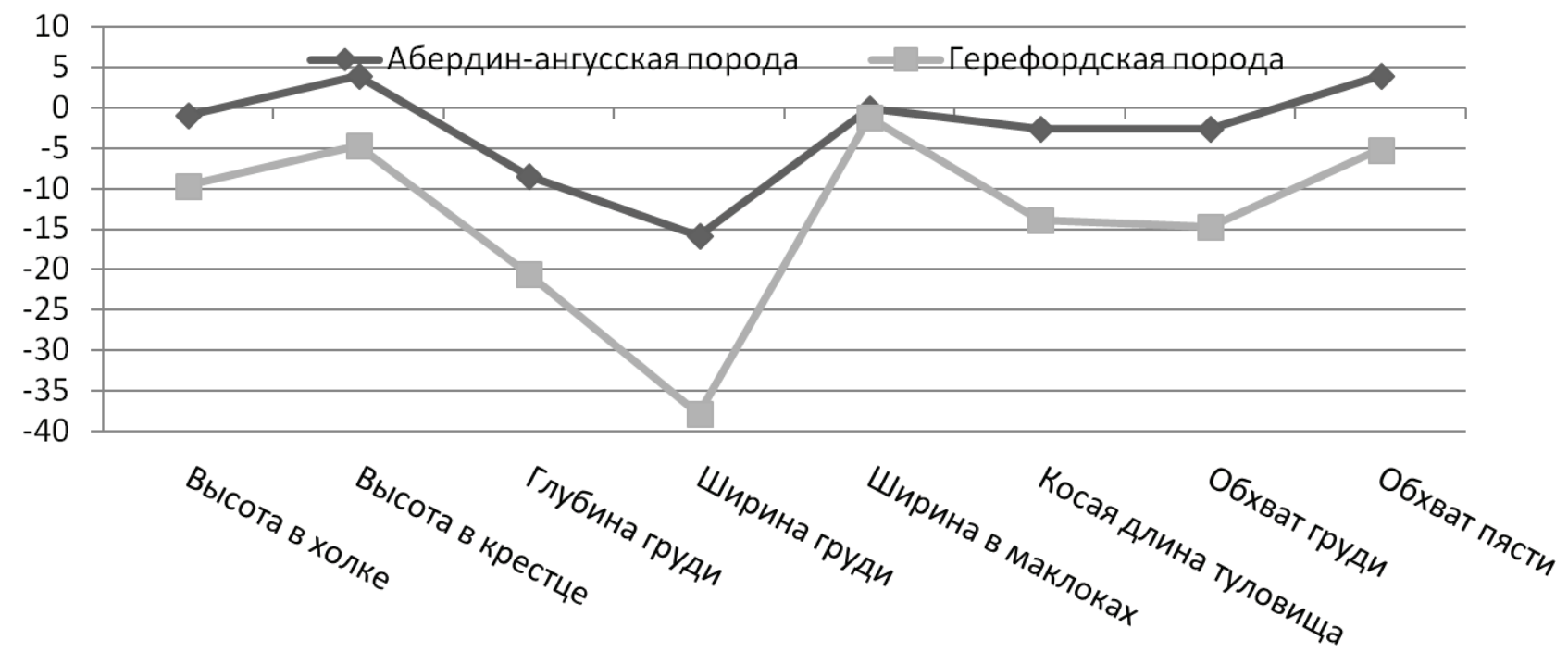

Рис. 1 - Экстерьерный профиль коров мясного направления продуктивности

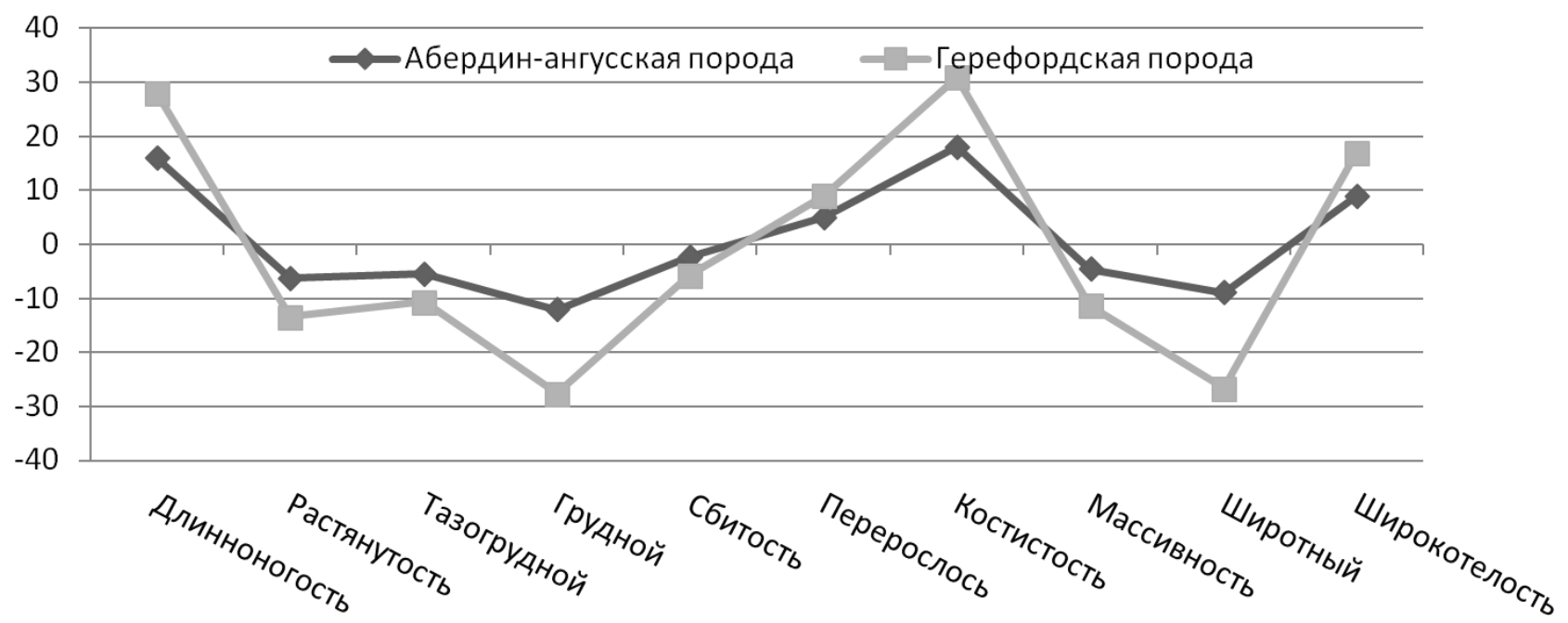

Рис. 2 - Экстерьерный профиль коров мясного направления продуктивности

нечности - 5,00, 15,00-14,77, 10,00-9,90 балла соответственно. По другим показателям больший балл имели коровы абердин-ангусской породы: телосложение - на 3,74, мускулатура 2,71, грудь - 3,34, холка, спина, поясница - 3,54, крестец - 1,35, окорока - 2,74, общий балл - на 17,75 соответственно.

Более полно экстерьер животных характеризуют индексы телосложения (таблица 3).

Индекс длинноногости коров абердинангусской и герефордской пород составил 49,24 и 47,04, что значительно больше стандарта для мясных пород, разница 13,7 и 9,7 \%. Высокое значение индекса является одним из показателей послеутробного недоразвития, что подтверждается данными о глубине груди. Индекс растянутости был меньше на 6,2 и 7,2 \% стандарта, это говорит о том, что некоторые животные обеих пород в стаде отставали в росте и развитии. Индексы тазогрудной и грудной у живот- ных абердин-ангусской и герефордской пород меньше стандарта на 5,4 \% и 12,1 \%, 5,2 \% и 15,5 $\%$, это объясняется недостаточно развитой грудью у коров. Индекс сбитости у исследуемых животных меньше на 2,2 и 3,4 \%, что считается допустимым для коров. Индекс перерослости больше стандарта на 4,7 и 4,0 \%, что также допускается. Индекс костистости больше на 15,3 и 11,2 \% стандарта, что указывает на некоторую грубокостность и грубость телосложения. Индекс широкотелости больше на 8,6 и 7,5 \%, это подтверждает, что абердин-ангусский и герефордский скот имеет типичные мясные формы.

Индексы телосложения коров абердинангусской породы были больше, чем коров герефордской породы: длинноногости - на 4,5\%, растянутости - на 1,0\%, тазогрудной - на 3,9\%, грудной - на 3,9 \%, сбитости - на 1,1 \%, перерослости - на 0,7 \%, массивности - на 2,1 \%, широтный - на 20,6 \% (P<0,001), широкотелости - на 


\section{1,1 \% соответственно.}

Экстерьерный профиль коров абердинангусской и герефордской пород, представленный на рисунках 1 и 2, подтверждает выводы, сделанные выше.

\section{Выводы}

Оценка экстерьера коров позволила установить, что животные абердин-ангусской породы имели лучшие мясные формы, чем герефордской.

\section{Библиографический список}

1. Алексеева, Е.И. Экстерьерные особенности коров герефордской и абердин-ангусской пород / Е.И. Алексеева, Т.Л. Лещук // Зауральский научный вестник. - 2015. - №1(7). - С. 9698.

2. Ефремов, А.П. Взаимосвязь показателей экстерьера и продуктивности коров в ФГУП «ОМское» / А.П. Ефремов, В.Н. Иванов, Т.Е. Тарасова,
Я.С. Архцкая // Молодой ученый. - 2016. - №2. - С. 311-315.

3. Алексеева, Е.И. Экстерьерные особенности коров абердин-ангусской породы. Научное сопровождение инновационного развития агропромышленного комплекса: теория, практика, перспективы / Е.И. Алексеева // Материалы 65-й международной научно-практической конференции. - Рязань, 2014. - Часть III. - С. 6063.

4. Кравченко, Н.А. Разведение сельскохозяйственных животных: для зо-отехнического факультета с.-х. вузов / Н.А. Кравченко. - 2-е изд., перераб. и доп. - Москва: Колос, 1973. 486 c.

5. Порядок и условия проведения бонитировки племенного крупного рогатого скота мясного направления продуктивности: производственно-практическое издание - Москва, 2012. -40 c.

\title{
COMPARATIVE CHARACTERISTICS OF THE EXTERIOR OF MEAT-TYPE COWS
}

\author{
Alekseeva E.I., Sukhanova S.F., Leshchuk T.L. \\ FSBEI HE "Kurgan State Agricultural Academy named after T.S. Maltsev » \\ 641300 Kurgan region, Ketovskiy raion, Lesnikovo v., \\ Tel./fax: +7 (35231) 4-41-40 \\ E-mail: rectorat@mail.ksaa.zaural.ru
}

Key words: cattle, cows, body measurements.

Currently, assessment of the external animal parametres, the identification of the relationship between the exterior and productivity is the most important task of breeders. Studies of exterior peculiarities of Aberdeen-Angus $(n=44)$ cows and White-faced $(n=39)$ breed were carried out in the farms of Kurgan region in accordance with the instruction "Procedure and conditions for carrying out valuation of meat-type breeding cattle ". Analysis of the exteriors showed that the cows of the Aberdeen-Angus breed were higher and larger than the White-faced cows. Thus, the height difference at withers and rump was $10.00(P$ $<0.001)$ and $11.55 \mathrm{~cm}(P<0.001)$, respectively. The cows of Aberdeen-Angus breed had larger chest depth, breadth and girth by $2.55(P<0.05)$, $3.04(P<0.001)$ and $18.63 \mathrm{~cm}(P<0.001)$, respectively, the oblique body length - by $12,88 \mathrm{~cm}(P<0.001)$, pastern girth by $2.4 \mathrm{~cm}(P<0.001)$. The constitution indexes of the cows of the Aberdeen-Angus breed were higher than those of White-faced cows: legs were longer by $4.5 \%$, length - by $1.0 \%$, pelvis-chest - by $3.9 \%$, chest - by $3.9 \%$, blockiness - by $1.1 \%$, overgrowth - by $0.7 \%$, massiveness - by $2.1 \%$, plumpness - by $20,6 \%(P<0.001)$, body width - by $1.1 \%$, respectively. Evaluation of cow exteriors allowed to state that the animals of Aberdeen-Angus breed had better meat parametres than White-faced cows.

Bibliography

1. Alekseeva, E.I. Exterior features of cows of White-faced and Aberdeen-Angus breeds / E.I. Alekseeva, T.L. Leshchuk //The Trans-Urals Scientific Vestnik. - 2015. - № 1 (7). - P. 96-98.

2. Interrelation of the exterior and cow productivity parametres of FSUE "Omskoye" / A.P. Efremov, V.N. Ivanov, T.E. Tarasova, Ya.S. Arkhtskaya // Young scientist. - 2016. - №2. - P. 311-315.

3. Alekseeva, E.I. Exterior features of cows of Aberdeen-Angus breed. Scientific support of the innovative development of the agro-industrial complex: theory, practice, prospects / E.I. Alekseeva // Materials of the 65th International Scientific and Practical Conference. - Ryazan, 2014. - Part III. - P. 60-63.

4. Kravchenko, N.A. Breeding of farm animals: for zootechnical faculty of agricultural universities / N.A. Kravchenko.-2nd ed., revised and upgraded. Moscow: Kolos, 1973. - 486 p.

5. The order and conditions for carrying out valuation of meat-type breeding cattle: production and practical publication - Moscow, 2012 . - 40 p. 